\title{
Tesoros moriscos y picaresca
}

\author{
Manuel Barrios Aguilera*
}

No es exclusiva de tiempos de los moriscos la fiebre de búsqueda de tesoros ocultos, pues, a lo largo de los siglos de la historia, anidó en las mentes de las gentes de las clases populares, las menos favorecidas de la fortuna, la esperanza de algún hallazgo, más o menos fabuloso, que viniera a cambiar el signo menesteroso de sus vidas. El fin de algún pueblo y su sustitución violenta por otro ha sido en todo tiempo jugoso caldo de cultivo para dar alas a estas imaginaciones, que algunas veces ha abonado algún ejemplo. No es casual, pues, que en la Península Ibérica, tan hollada por toda clase de pueblos y civilizaciones, el fenómeno revista una especial dimensión; y mucho menos, que sean los "moros", en todos sus sucesivos estatus, los que hayan disparado las más frondosas especulaciones, habida cuenta de su peripecia histórica, tan densamente dramática, tan dada a crear fantasías desbordadas, que cierta literatura romántica, y luego, y acaso siempre, la erudición localista han alimentado y aun prolongado hasta nuestros días ${ }^{1}$.

\footnotetext{
* Universidad de Granada.

1 El tema de los tesoros posee vertientes que lo emparentan, y aun confunden, con lo fabuloso, lo misterioso o lo mágico. De ahí que haya calado tan profundamente en las culturas de todos los pueblos, pero especialmente en los que, como el gallego (ver, por ejemplo, el Grande livro de San Cipriano ou tesoros do feiticeiro, recurrentemente editado en diversas versiones, hasta el popular Ciprianillo) o vasco, hunden sus señas de identidad en lo ancestral y remoto. Si bien nuestro planteamiento está muy alejado de cualquier soplo fantástico, no estorbará seguramente remitir a obras como la de Álvaro CunoueIRo, Tesoros y otras magias. Barcelona, Tusquets, 1984, que, pese a su exclusiva dimensión literaria, permite un primer acercamiento a una temática no muy frecuentada por el historiador, pero que evidencia una componente histórica no desdeñable. Ayuda a esta comprensión la edición del antropólogo César Antonio Molina, cuya introducción y notas son una fuente excelente de sugerencias conceptuales y bibliograficas, que, además, nos permite la remisión sin riesgo a quien desee profundizar en esta temática apasionante. Nótese que, si bien los “moros" (mouros) son los protagonistas incuestionables de esta obra (compilación de relatos breves), el significado es muy distinto del que corresponde a la rea-
} 
Las del Reino de Granada, donde la dominación musulmana y consecuentemente la peculiaridad «oriental» de su civilización fueron más duraderas y perdurables, son las tierras hispanas más proclives a cualquier tipo de manifestación de esta índole. Máxime que el final de la presencia física de este pueblo se produjo tras dos guerras muy cruentas: primeramente, la de conquista en tiempos de los Reyes Católicos (1482-1492); luego, la de los moriscos (1568-1570). Ambas, seguidas de deportaciones y repoblaciones masivas que sellaron el nuevo rumbo del Reino en la época moderna ${ }^{2}$.

lidad histórica del término. No es casual, sin embargo, que, salvadas las distancias, conecte con algún escritor o viajero romántico, sugestionado por los más genuinos (?) moros del sur, como Washington Irving en sus Cuentos de la Alhambra. Granada, Ed. Padre Suárez, 1965; ed. original, 1832; especificamente, la "Leyenda del legado del moro", págs. 201-221, o el barón Charles de DAVILLIER en su Viaje por España. Madrid, Adalia, 1984; cap. 10, "La Alhambra», que no podía dejar de tener eco en alguna literatura costumbrista local de esta tierra de tan eminente raigambre musulmana. (Recuérdense, por ejemplo, entre muchos más que se podrían rastrear entre una literatura localista de no demasiada proyección: MONTES, Luis de, «Tradiciones granadinas. La Torre de los Siete Suelos. Cuentos fantásticos", La Alhambra, época romántica, vol. $2^{\circ}, 1839$, págs. 103-108; Montells y NADAL, Francisco de Paula, "La cueva de Piñar", en La Alhambra. Relatos de Granada. Recuerdos de Andalucia, Granada, Albaida, 1991, págs. 307-310, ed. original, Barcelona, 1863 , etc.). No muy alejado de estas inspiraciones se halla Ignacio GOMEZ DE LIAÑo, cuando, en su imaginativo Los Juegos del Sacromonte, Madrid, Editora Nacional, 1975 , pág. 192, relatando el episodio de los “libros plúmbeos" granatenses - véase, ut infra, nota 5-, escribe: «Buscar tesoros era una exploración no exenta de misterio; era un ir a la zaga del encuentro de la fortuna feliz, de la sorpresa, de lo extraordinario. Buscar tesoros empieza a parecer como si fuese buscar otra cosa, algo que compromete al entero psiquismo, que le pone en el riesgo de recorrer un territorio de agazapadas sorpresas. No sólo era un encontrar y un sorprender el tesoro, sino que el tesoro era la realidad oculta que se iba a descubrir, y de ese modo, descubierta la realidad, uno se haría rico, podía ya estar seguro de su fortuna, de su buena estrella, y es que esa realidad oculta del tesoro es una materia llena de poderes, guardada por fuerzas de moniacas. Buscar tesoros, en este ambiente mágico-místico, es exponerse a encontrarse con una realidad de la que el tesoro concreto que pudiera hallarse no es más que mero signo sensible o sacramento. Buscar tesoros es vivir una ficción maravillosa y rica...". Desde la perspectiva etnoantropológica, entendemos de superior interés el trabajo de PRovanSAL, Danielle, "Tesoros y apariciones: la prohibición de la riqueza", Demófilo. Revista de cultura tradicional de Andalucia, 15, 1995, págs. 37-61, que si bien alude a lugares históricos cargados de sugerencias para el estudioso del mundo morisco del Reino de Granada, se fundamenta en un trabajo de campo, encuestas orales, excelentemente articulado con el nivel teórico, aunque desestima la vertiente histórica, tanto en su fundamentación primaria (la archivistica), como secundaria (bibliográfica).

2 Sobre la guerra de conquista del Reino de Granada, véanse: LADERo QUESADA, M. Á. Castilla y la conquista del Reino de Granada, Valladolid, Universidad, 1968 (3 $3^{\mathrm{a}}$ ed., Granada, Diputación, 1993) y Carriazo ARroquIA, J. de M. Historia de la Guerra de Granada, en tomo XVII-1 de Historia de España, dir. por R. Menéndez Pidal. Madrid, Espasa-Calpe, 1969. Sobre la de los moriscos se hallará una pequeña guía biblio-historiográfica en nuestro Moriscos y repoblación. En las posirimerias de la Granada islámica, Granada, Diputación, 1993, págs. 33-41, y relatos breves, pero muy precisos, de los hechos en CARO BAROJA, J., Los moriscos del Reino de Granada. Ensayo de historia social. Madrid, Istmo, 1976 (1ª ed., 1957) y DomínGUEz ORTIz, A. y VINCENT, B., Historia de los moriscos. Vida y tragedia de una minoria. Madrid, Ed. Revista de Occidente, 1978 (varias reediciones posteriores). 
En este contexto hay que inscribir el tema que nos ocupa, que cronológicamente nos traslada a los años inmediatamente posteriores a la expulsión de los moriscos del reino granadino y su distribución por otros reinos castellanos. Conviene recordar que las primeras deportaciones se produjeron cuando aún la guerra no había concluido, so pretexto de eliminar las ayudas que los moriscos alzados en armas podían recibir de los "de paces» y evitar las cuantiosas huidas de los más útiles a los espacios serranos a engrosar los ejércitos rebeldes ${ }^{3}$. Ésta es una historia suficientemente conocida en sus líneas generales que no cabe repetir aqui; empero, procede invitar a la evocación de la enorme tribulación que tan quirúrgica medida produjo en el común de la población vencida, en tantos casos $\sin$ haber luchado, que no es difícil imaginar empeñada en salvar sus pequeñas riquezas, penosamente ahorradas las más de las veces tras muchos años de laborioso trabajo y frugalidad.

El recurso sería, lo fue, ocultar esos ahorros en los campos y casas, con la esperanza de que algún día podrian volver a esta tierra, su tierra, a recuperarlos, sobre todo cuando no era difícil adivinar que el penoso viaje del exilio en modo alguno garantizaba el respeto de esa riqueza, no pudiendo siquiera hacerlo de la propia integridad personal... Peor sería la perspectiva de quienes como única salida a su derrota iban a encontrar la esclavitud, si salvaran la vida. Valga un ejemplo, entre muchos posibles,

\footnotetext{
El proceso repoblador de fines del siglo XV puede estudiarse en las compilaciones (en ambos casos de artículos de gran importancia) de LADERo QueSADA, M. Á., Granada después de la conquista: repobladores y mudéjares. Granada, Diputación, 1993 (19. reed., 1988) y LÓPEZ DE COCA, J. E., El Reino de Granada en la época de los Reyes Católicos: repoblación, comercio, frontera. Granada, Universidad, 1989 (2 vols.). Rafael G. Peinado SANTAELLA ofrece un exhaustivo balance y guía de tan compleja temática en su extensa ponencia "La repoblación del Reino de Granada. Estado de la cuestión y perspectivas de la investigación", en Actas del Coloquio de la V Asamblea General de la Sociedad Española de Estudios Medievales. Zaragoza, Diputación General de Aragón, 1991, págs. 273-334. La repoblación de Felipe II cuenta con un colectivo recentisimo donde se abordan monográficamente las más significativas cuestiones del proceso repoblador: Barrios Aguilera, M. y andujar Castillo, F. (eds.), Hombre y territorio en el Reino de Granada (1570-1630). Estudios sobre repoblación. Almería, Instituto de Estudios Almerienses, 1995. En nuestro Moriscos y repoblación..., op. cit., págs. 43-90, se contiene un estado de la cuestión actualizado sobre la segunda repoblación.

3 Un preciso relato la expulsión y sus circunstancias, en VINCENT, B., "La expulsión de los moriscos del Reino de Granada y su reparto en Castilla", en Andalucía en la Edad Moderna: economia y sociedad. Granada, Diputación, 1985, págs. 215-266. Sobre las verdaderas actitudes de los llamados "moriscos de paces", véase nuestro trabajo "Entre la guerra y la expulsión: consideraciones sobre una nómina de moriscos huidos", en Actas del II Congreso de Historia de Andalucía. Andalucía Moderna, Córdoba, Caja de Ahorros de Córdoba, 1995, tomo I, págs. 311-329, del que se ha dado una versión extractada bajo el título "Moriscos 'ydos a la Sierra' en la guerra de las Alpujarras", en Mélanges Louis Cardaillac. Zaghouan (Tunisie). Fondation Temimi por la Récherche Scientifique ef l'Information (FETERSI), 1995, tome ler., págs. 73-83.
} 
que ha dejado profunda huella en la memoria popular: tras la captura del peñón de Inox (Almería), uno de los hechos bélicos más atroces de la guerra de los moriscos, además de cuantiosísimos muertos resistentes, unos 400 , fueron cautivados y reducidos a esclavitud: 2.700 "cabezas" -en estimación del cronista Luis del Mármol Carvajal-, entre mujeres y niños. El peñón, fuerte y arriscado, casi inaccesible, había servido de lugar de refugio y resistencia de todos los moriscos de la zona (de ahí tan elevadas cifras); la lucha fue terrible, pues al afán desesperado de defensa de los moriscos, se opuso el incontrolado apetito de botín de los asaltantes. La suerte estaba echada. Las riquezas capturadas por los vencedores cristianos han sido evaluadas como copiosisimas por los cronistas e historiadores; cabe pensar, sin embargo, que fueran sólo una corta parte de las que arrastraron hasta aquel peñón quienes habian previamente huido con todos sus enseres y pertenencias de las tierras aledañas. No es casualidad que pronto el monte se convirtiera en atractivo lugar de buscadores de tesoros, que todavía en tiempos recientes llegaron a convertirlo en un verdadero "colador», tal era el número de agujeros que horadaban su superficie ${ }^{4}$.

Otro ejemplo de naturaleza muy distinta, pero que abunda en nuestra argumentación, es el de los descubrimientos granadinos de 1595. Fueron dos exploradores de tesoros quienes removiendo tierras en la colina de Valparaíso hallaron los primeros testimonios que habian de sustentar el mito sacromontano. Bien conocían los falsarios la mentalidad popular; en este caso, ni siquiera faltaba el abrigo de un atractivo añadido, casi irresistible, la existencia de cuevas y restos de construcciones antiguas. El último de los estudiosos del hecho sacromontano, Julio Caro Baroja, refiriéndose al origen de los hallazgos de Valparaíso, relata cómo participan en el descubrimiento personas del pueblo «guiadas por creencias también popularísimas entonces y después". "Es conocida -agrega- la existencia de ciertos librillos que en algunas partes llamaban 'gacepas' o 'gacetas' y en otras 'recetas', y en los que, de modo más o menos críptico, se indi-

\footnotetext{
4 Véase nuestra comunicación «Del morisco como botín. Noticia sobre la presa del Peñón de Inox en la segunda guerra de Granada», presentada en la "IV Reunión Científica de la Asociación Española de Historia Moderna", en prensa. Agradezco al profesor Francisco Andújar la primera información sobre la "fiebre" de búsqueda de tesoros en el peñón de lnox y la posibilidad de patear el terreno de la mano de tan buen guia y comprobar con algún lugareño la tradición. En ningún momento se intentó algo más que una visita. Entendemos que un trabajo de campo requiere una formación específica que reconocemos en otros especialistas que la han acreditado; véase el citado artículo de ProvanSAL, D., "Tesoros y apariciones...", centrado en el Campo de Níjar precisamente.
} 
ca la existencia de tesoros en determinado lugar. En Granada estos librillos de recetas eran muy populares durante el siglo XVI..." 5

Nuestra propuesta es mucho más prosaica, también más extrapolable a lo cotidiano, pues carece del halo heroico del hecho bélico y del extraordinario y misterioso del mito. Se inscribe en lo que debió de ser moneda corriente de los años posteriores a la expulsión de los moriscos del Reino de Granada. La propia variedad casuística de los ejemplos que traemos tiene el denominador común de esa cotidianeidad que le asignamos ${ }^{6}$. La misma facilidad con que hemos tropezado con esa documentación archivística -al hilo de bien distinta ocupación - la entendemos como prueba indirecta de su relativa abundancia, que invita a una búsqueda más deli-

5 Las falsificaciones en la historia (en relación con la de España). Barcelona, Seix Barral, 1992, pág. 119. Luego, relata el insigne antropólogo la historia del hallazgo, con algún detalle muy significativo de cómo el fin del mundo morisco era tierra abonada para estas aventuras: “...y parece que un capitán de infantería, vecino de Sevilla, que cayó preso de los moriscos durante la guerra de las Alpujarras, adquirió uno en que, por una parte, se indicaba que los cristianos, al tiempo de la derrota de Don Rodrigo, habian cerrado una magnífica mina de oro, propiedad de éste (...) El librillo pasó a manos de dos buscadores de tesoros..." (Ibidem, págs. 119-120). (Los historiadores coetáneos locales, Antolinez de Burgos y Bermúdez de Pedraza, hablan de «memorial" y ureceta", respectivamente - ANTOLINEZ DE BURGOS, Justino, Historia eclesiástica de Granada, ms. del Archivo de la Abadia del Sacromonte. Granada, 1620, fol. 229 rº, y BERMÚDEZ DE Pedraza, Francisco, Historia eclesiástica, principios y progresos... de Granada. Granada, 1638, pág. 266b, respectivamente). Por su parte, fray Dario CABANELAS ha subrayado el hecho de que la existencia de restos de construcciones antiguas afirmaba la opinión popular de que allí debian encontrarse tesoros ocultos, "suposición frecuente respecto de cualesquier ruinas situadas en país anteriormente ocupado por los musulmanes" (El morisco granadino Alonso del Castillo. Granada, Patronato de la Alhambra y Generalife, 1991², pág. 262).

Quien quiera conocer la historia de los hallazgos sacromontanos deberá saber que van siendo legión los historiadores antiguos y modernos que se han ocupado de su estudio; para no hacer innecesariamente larga esta nota, me permito remitir al ensayo introductorio de Miguel L. LOPEZ MuÑoz a la edición facsimilar de la obrita de don Zótico Royo Campos, Reliquias martiriales y Escudo del Sacro-monte. Granada, Universidad, 1995, págs. VII-CIV, que no sólo es una puntual síntesis de los hechos, sino un preciso estado de la cuestión bibliográfico (Carlos Alonso, Antonio Bonet Correa, Darío Cabanelas, Julio Caro Baroja, José Godoy Alcántara, Ignacio Gómez de Liaño, Miguel José Hagerty, T. D. Kendrick, Manuel Sotomayor, etc.) y un cumplido recorrido historiográfico (Francisco Bermúdez de Pedraza, Juan Cristóbal Calvete de Estrella, Alonso del Castillo, Adán Centurión, Luis de la Cueva, Diego Nicolás Heredia Barnuevo, Gregorio López Madera, Miguel de Luna, Luis del Mármol Carvajal, Cristóbal de Medina Conde, Diego de la Serna Cantoral, etc.).

6 Valga un ejemplo extraído de una documentación distinta de la que fundamenta esta pequeña aportación: se trata de una carta del Marqués de los Vélez en que se contienen diversos asuntos, uno de los cuales es el hallazgo de un tesoro por unos moriscos:

"Aquí me han escrito que [en] término de mi villa de Alhama, en una hortichuela de un Bastida, vasallo mío, an sacado un tesoro, y que lo sacó un Santacruz de Murçia y otros de Alcantarilla, y que lo an llevado a esa çibdad a fundir, y que a ydo con ellos uno que llaman Calvillo. Sabed sy an ydo ay a la casa de la moneda a batir la moneda, y enbargadlo hasta que se os enbie ynformaçión porque no lo transporten y estemos a derecho sobre ello, por avello sacado de mi villa de Alhama, por yndustria sin mi liçençia" (Archivo Ducal de Medina Sidonia, leg. 1298; $\sin$ fecha). 
berada y sistemática. Dos argumentos que elevan documentación y temática muy por encima de lo anecdótico o baladí, pues son un buen elemento para calibrar parámetros mentales a los que se atenía la sociedad de la época, al menos en esa coyuntura de sociedad-de-repoblación en que se inscribe espacial y cronológicamente. Los legisladores y memorialistas de la segunda repoblación tuvieron bien presente esta realidad; así, un memorial sobre incorporación de los bienes confiscados a los moriscos e instrucciones sobre la repoblación, de fecha 5 de marzo de 1571, hablando de las casas del Albaicín y de la Alcazaba de Granada se dice:

"Y en esto es menester poner luego remedio porque, avnque se pone cuidado en guardallas, con cobdiçia de buscar lo que los moriscos tenían escondido, de noche las caban y derriban, y no se puede remediar avnque se castigan algunos sobrello"?

$Y$, poco después, en la fundamental «Real Cédula e Instrucción para la repoblación y administración de la hacienda confiscada a los moriscos" de fecha 22 de marzo de 1571 -documento minucioso hasta la prolijidad por el enorme rubro de cuestiones trascendentales que abarca-, el legislador no olvida consagrar un apartado a los tesoros:

"26. Si se hallaren y descubrieren algunos tesoros en el dicho reyno, hase de guardar cerca desto la orden que habemos dado por la provisión de lo que se concede a los pobladores: y de lo que procediere de aquello, o de otros qualesquier tesoros que se hallaren y descubrieren en otras qualesquier partes del reyno de Granada se terná la misma quenta y razón en los dichos dos libros que ha de haber en lo demás" ${ }^{8}$.

Los etnólogos y antropólogos han entendido bien esta significativa dimensión - me permito remitir al citado trabajo de D. Provansal-; por ello, es extraño que en la tan recurrida investigación de lo morisco se haya olvidado este tema, sobre el que se impone volver con mejores pertrechos, dado que los datos archivísticos, más o menos dispersos, no parecen escasos.

Debieron ser incontables las peticiones que moriscos y repobladores elevaron al rey en las décadas inmediatas a la finalización de la guerra; la

7 Apud Birriel Salcedo, M. M., La tierra de Almuñécar en tiempo de Felipe II. Expulsión de moriscos y repoblación. Granada, Universidad, 1988, págs. 259-260.

\& apud Oriol Catena, F., La repoblación del Reino de Granada después de la expulsión de lo moriscos. Granada, Universidad, 1987 (es ed. facsímil, con una introducción de M. Barrios Aguilera). 
variedad y abundancia de las que se conservan en los archivos pueden dar una idea de ello: desde interesadas y aun abusivas demandas por cristianos viejos de suertes ordinarias de repoblación y "ventajas" en las tierras del Reino granadino, por razonables o peregrinos méritos, hasta el grito desesperado de moriscos que solicitan la gracia de poder recomponer su destrozada familia en el exilio o volver a su pueblo aduciendo continuados y leales servicios a la Corona, etc. ${ }^{9}$ Entre ellas, debieron de abundar las peticiones de permiso para recuperar lo que en la tribulación habían ocultado en sus casas o en sus tierras; sus "tesoros", en fi".

Es el caso, por ejemplo, de dos moriscos granadinos radicados a la sazón (acaso en 1580) en el Reino de Aragón. Se trata de Luis Gostín, vecino de Jarque, y de Luis Mafof, vecino de Sestrica, en la actual provincia de Zaragoza, que piden licencia al rey para recuperar los "ocho o nuebe mil ducados", que "dexamos escondidos" al salir del Reino de Granada. No señalan el lugar en su carta, pero sí ofrecen las únicas garantías (y el señuelo) que les es dado ofrecer, es decir: recuperar el dinero "ante la justiçia en cuyo distrito está el dinero o persona que se nos señale, tomarlo libremente las dos partes y lleballas [a] Aragón, dando y dexando de todo la terçia parte a vuestra magestad» ${ }^{10}$. No es la petición lo más llamativo, que como deciamos debió ser bastante común; sí, seguramente, la cuantía del "tesoro", que no parece nada común.

De bien distinta índole es la petición de un cristiano viejo, vecino de la ciudad de Valencia, Diego de la Tovilla, quien, en carta de 27 de febrero de 1580, solicita del rey licencia para ir a Serón, en el valle del Almanzora almeriense, para recuperar "cierta cantidad de dinero" que escondieron los padres de una esclava suya, que fuera vecina de aquella villa, su informadora. El solicitante apostilla que "el oficial que hubiere de hallarse presente por parte de vuestra magestad quando se sacare dicho dinero sea el que administra el corregimiento de la dicha villa de Serón, o puesto por su mano; esto suplica por escusar los gastos que se harian lleuando el dicho oficial de la corte, mayormente siendo como está dicho cosa inçierta" " 1 . La característica de la petición no alivia la sordidez de la misma, solamente paliada si la recuperación de ese dinero conllevara la manumisión de la esclava.

9 Puede dar una buena idea la "relación" de 112 de estas peticiones que se contiene en una pieza de 19 fols., que en definitiva no es más que un índice de regestas, cuyas versiones completas e individualizadas se encuentran dispersas en varios legajos (Archivo General de Simancas. Cámara de Castilla, leg. 2180).

10 Archivo General de Simancas. Cámara de Castilla, leg. 2180, pág. 78.

" Ibidem, ibidem, pág. 98. 
Por su parte, y es mera expresión de la anunciada amplitud casuística posible, Roque de Estrada, cristiano viejo, vecino de la ciudad de Granada (acaso también en ese año de 1580) demanda licencia al rey para buscar y sacar de "devaxo de tierra", en el término de Ugíjar, en la Alpujarra, «muchas cosas que los moros escondieron al tiempo de la rebelión que hizieron, entre las quales ay alguna cantidad de seda». Ni que decir tiene que el solicitante estaba "presto de entender luego en lo buscar con la solenidad que se requiere" 12 .

El caso que nuclea esta aportación es el que justifica su título. Su singularidad lo aparta sin duda de lo que debió ser moneda más frecuente, que acaso quede mejor referida en los precedentes:

Los tres jueces que entienden en la justicia de lo tocante a la rebelión de los moriscos del Reino de Granada informan al rey de que en el mes de mayo de 1574 les fue denunciado

"vn Baltasar de Portales y otros, diziendo auer ydo a vna casa del Albayzín de Granada, que auía sido de morisco, y con maña auían hecho salir a vna muger que bibuía en ella, llebando consigo vn morisco que para este efeto auian traydo de los lleuados fuera de el Reyno, y que estando dentro de la casa, la hauían çerrado y estado más de dos horas dando golpes en la pared de vna sala baxa, donde se hallaron señales de lo escondido que buscauan (...) y el Portales fue preso y lo está en la carçel desta audiençia» ${ }^{13}$.

Aducen, en fin, los jueces una cuestión de competencias, pues siendo el dicho Portales procurador del Santo Oficio, «se nos ha ymbiado a dezir

12 Ibidem, ibidem, pág. 18.

13 Ibidem, leg. 2175, fol. 1 ro. El expediente completo del caso resulta de la conjunción de las cartas de Pedro de la Fuente a Juan Vázquez de Salazar y de los tres jueces al rey con el traslado de las declaraciones de los testigos que más abajo se expresan y desarrollan, que componen de hecho una pieza de 18 fols., sin numeración, de manera que la que usamos ha sido dispuesta por nosotros para precisar las referencias textuales.

Sobre el tribunal de los «Tres jueces", véase BIRRIEL SALCEDO, M. M., "Las instituciones de la repoblación del Reino de Granada (1570-1592)", en BARRios AGUILERA, M. y F. Andúsar CASTILLA (eds.), Hombre y territorio..., op. cit., págs. 92-97. Se trata de un ministerio de justicia, dentro del Consejo de Población, que entiende en lo referente al delito de rebelión de los moriscos y todo lo de él derivado, tanto en lo civil como en lo penal. "Se constituye como un tribunal o supremo dentro de sus competencias, ya que contra sus sentencias no cabe apelación ni recurso, ni tan siquiera ante el Consejo de Castilla. Podía actuar bien de oficio o a petición de parte" ("Las instituciones...", pág. 93).

Para una localización del escenario de los hechos y como ayuda a la contextualización de los mismos, cfr. VINCENT, B., «El Albaicín de Granada en el siglo xVi (1527-1587)", en Andalucia en la Edad Moderna..., op. cit., págs. 123-160. 
quel conoçimiento desta causa les perteneçe", lo que ha sido contradicho por el fiscal del juzgado que rechaza la remisión «diziendo que el delicto es graue, calificado de hurto de hazienda a vuestra magestad perteneçiente y de quebrantamiento de casa y auerse traydo para ello morisco [de] fuera del Reyno». Se aduce además por los tres jueces "queste Portales no es de los familiares expresados en la concordia, en caso que della se quisiesen aprouechar" ${ }^{14}$.

El resumen de los tres jueces es escueto y poco matizado, pero correcto. Su carta es de 2 de julio de 1574. Conocemos una carta, de fecha 29 del mismo mes, enviada por Pedro de la Fuente, escribano de cámara y del consejo de justicia en Granada, a Juan Vázquez de Salazar, aun más escueta y que asimismo incide en los aspectos competenciales urgiendo su pronta solución "porque ay preso y porque quede asentado con este caso los negoçios semejantes de adelante" ${ }^{15}$.

Prescindimos de los aspectos jurisdiccionales, en todo caso insuficientemente documentados, para centrarnos en los hechos que los suscitan, dentro del hilo argumental que hemos insinuado arriba. En tal sentido son expresivos los testimonios que el citado Pedro de la Fuente adjunta a su aludida misiva, frutos de la deposición sucesiva del propio protagonista principal, de su cuñada y de un testigo indirecto, Bartolomé de Guevara, vecino de Granada, en la parroquia de San Andrés del Albaycín, que relata lo que a su vez le había contado esta mujer, la propia cuñada de Portales, $y$ del escribano ${ }^{16}$. Los dos últimos son testimonios demasiado homogéneos, escasamente diferenciados, pero suficientes para rehacer con algún detalle la actuación del encausado y de sus ayudadores; más simplificado en el relato de la peripecia es el de Portales, aunque es el único que incide en las motivaciones de su acción.

Según su propia deposición, Baltasar de Portales, vecino de Granada, de cuarenta y dos años de edad y procurador del Santo Oficio en esta ciudad, había sido informado, cuando estaba en el local de la Inquisición, en la Semana Santa de 1574, por un Fulano de Fuentes, vecino asimismo de Granada, de la existencia de un tesoro oculto en una casa que fuera de morisco expulso de la collación de San José, en el Albaycín, que ahora pertenecía a su cuñada, viuda de su hermano Alonso de Portales, que a su vez la tenía alquilada a un tal Vallejo. La información era de buena

14 Archivo General de Simancas. Cámara de Castilla, leg. 2175, fol. 1 ro. (En las notas sucesivas nos limitamos a señalar los folios, pues todas las referencias son de la misma pieza).

15 Fol. 2 ro.

16 Fols. $5 r^{2}-9 v^{0}$. 
tinta, al parecer, pues el tal Fuentes, cuando ejercía de alguacil con Osorio de Ávila en Caravaca, había conocido a un morisco, cuyo nombre no sabía, pero que le había proporcionado las señas inequívocas del lugar. Según Portales, es este Fuentes quien lo incita y anima, quien lo acompaña y actúa golpeando la pared de la casa donde supuestamente estaría escondido el tesoro, y que nada hallan; la mujer de Vallejo había dado permiso para que entraran los buscadores yéndose a la casa de la cuñada de Portales, que como propietaria del inmueble había mediado explicando la operación y garantizando "que si algo huuiese se auia de registrar», como era preceptivo ${ }^{17}$. Asi relata el encausado los hechos:

«...y entró el dicho Fuentes y este confesante con él en la dicha casa y en la sala baxa enfrente de la puerta della, poniendo vna silla ençima de vna tinaja y vna tabla, y el dicho Fuentes subió ençima, y con vna achuela que llebaua tocó en la pared algunos golpes como en ella eran hasta que hallaron vn agujero mechinal como por él pareçe atapado con vna pella de yeso blanco, y en él no se halló ninguna cosa, ni en otra parte de la dicha casa; y se salieron llenos de poluo, y dixeron a las susodichas cómo no hauian hallado nada...” 18

El relato que se obtiene conjugando las declaraciones de Bartolomé de Guevara y de María de Morales, viuda de Alonso de Portales, es muy distinto al del encausado; más extenso y detallado, excepto en el comienzo.

La deposición de Guevara, hombre de treinta años (según se anota al final de su declaración), se produce el día 4 de mayo de 1574 ante el escribano Pedro de Hojeda, y afirma el declarante reproducir la conversación que tuvo con María de Morales siete u ocho días atrás. Del comienzo del testimonio se desprende, bien que no se diga explícitamente, que la cuñada de Portales debía tener a este Guevara por hombre de entendimiento y buen criterio. He aquí el comienzo de aquella conversación tal como la reproduce el escribano: “¿No sabrá vuestra merçed cosas nueuas que ay por acá?", le pregunta ésta. "No sé cosa ninguna», responde Guevara. "Y la dicha viuda le dixo a este testigo: Sabrá vuestra merçed que aquí bino Baltasar de Portales, mi cuñado, pocos días a, [a] puesta de sol, con otro honbre que quedó en la calle..." 19

Bartolomé de Guevara es testigo indirecto, es el que hace la declaración más extensa y matizada, y en efecto parece reproducir lo que le con-

\footnotetext{
Fols. $5 r^{0}-5 v^{\circ}$.

Fols. $5 v^{0}-6$ ro.

Fol. 6 ro.
} 
fesara Maria de Morales. Según esta versión, Baltasar de Portales le había dicho a su cuñada:

\begin{abstract}
«Señora, aquí viene un honbre ques alguazil mayor de vn lugar (que no se acordó del nonbre del dicho lugar) y trahe vna çedula del dueño de la casa que vuestra merçed conpró, en que dize que dentro en ella ay vn secreto. $Y$ que la dicha biuda le auía respondido: ¿Ese secreto no lo beriamos todos?. Y que el dicho Baltasar de Portales le auia respondido a la dicha su cuñada: No es tanto como eso, ques cosa poca de hasta trezientos o quatrocientos ducados; y no le dé a vuestra merçed pena, que si algo ay, registrarse tiene. $Y$ el dicho Baltasar de Portales, diziendo esto, rogó a la dicha viuda, su cuñada, que llamase a su casa a su vezina, ques su casera, que biue en la casa donde venía la çédula” ${ }^{20}$.
\end{abstract}

A continuación, Portales pidió a su cuñada que "entretubiese" en su propia casa, la que ella misma habitaba, que quedaba pared por medio respecto de la objeto de los hechos, "por dos o tres horas", a la mujer de Vallejo, "mientras que buscaua lo que benía en la memoria". Así se hizo. Entonces, Portales y el desconocido penetraron en la casa de la búsqueda, y cuando lo hubieron hecho atrancaron la puerta por dentro y encendieron lumbre para «buscar lo que querian». Poco después, a petición del acompañante, Portales hubo de ir a pedir a la "casera" (se refiere a la mujer de Vallejo), "estando como dicho es con la dicha biuda", la llave de la planta baja de la casa, que efectivamente le fue entregada. Dentro ya de esta sala baja, en la pared de enfrente de la puerta de entrada, cerca del techo, dieron muchos golpes durante dos horas; cesados estos golpes, "estubieron callando y con silençio espaçio de tienpo de otra hora", hasta que se hizo de noche. A la vista de que los hombres no salian, las dos mujeres se fueron a la casa de autos y llamaron a la puerta; entonces, "los susodichos abrieron la puerta y salieron sacudiéndose el polbo y diziendo: no hemos hallado nada, que todo es ayre. $Y$ el dicho honbre [que] estaua con el dicho Baltasar de Portales no habló palabra alguna, antes se cubrió e arreboçó la cara, de arte que no pudiese ser conozido" ${ }^{21}$.

La actitud misteriosa del acompañante extrañó al declarante Guevara, de ahi que interrogara a su informadora, "con sospecha de que el dicho honbre fuese morisco o el dueño de la dicha casa llebado del Reyno, si el dicho honbre le vido trujese espada". La respuesta es que no, "porque si la llebara, lo biera» ${ }^{22}$. También ella había sospechado que fuese morisco.

\footnotetext{
Fol. 6 vํ.

Fols. 6 vo -7 o.

Fol. $7 v^{\circ}$.
} 
Una vez que los dos hombres se hubieron ido, las mujeres fueron a la sala donde se habian producido los golpes y vieron picada la pared que está enfrente de la puerta, $y$ en ella hallaron un agujero o concavidad pequeña, "que cabría vn chapín", y una pella de yeso muy blanca, "que daua muestra averse con aquella atapado el agujero y después enluzido enzima» ${ }^{23}$. Hasta aquí la declaración de Guevara.

La de María de Morales, viuda de Alonso de Portales y cuñada del inculpado (mujer de treinta años y analfabeta, según consta al final de su declaración), se produce el mismo día que la precedente, ante el escribano Hurrutia. Es básicamente coincidente con la de Guevara, aunque algo menos detallada. Añade al comienzo que su cuñado fue a verla a eso de las cinco de la tarde, y habla de un «silo-thesoro» en la casa alquilada a Vallejo, e insiste en que se había de registrar, repitiendo casi a la letra lo de su probable cuantía, etc. Ante la necesidad de sacar a la mujer de Vallejo para proceder a la búsqueda, «esta testigo (es decir, María de Morales) le dixo que la muger del dicho Ballejo se auía de yr a criar çierta seda, que aguardase que se fuese y después se sacaría". Es el propio Portales el que parece disuadir de aprovechar esa circunstancia. No se habla del silencio de una hora tras las dos de golpes; sí se reitera casi textualmente lo de la inexistencia de tesoro alguno. Cambia sólo respecto de lo confesado por Guevara que María de Morales habría entrado en las casa alquilada a Vallejo al día siguiente ${ }^{24}$.

Lo más significativo y diferencial de la declaración, por el tono exculpatorio que en nuestra opinión tiene para su cuñado, es lo que se dice más adelante, y es

"que esta testigo no les vido a el dicho Portales ni al dicho honbre sacar ninguna cosa; mas de que el dueño de la dicha casa dizen todos los que le conoçian que hera muy rico, y teniendo sospecha de lo susodicho, su marido de esta testigo algunas vezes yzo cabar a sus criados en algunas partes de la dicha casa para ver si auía alguna cosa, y nunca hallaron ninguna cosa» ${ }^{25}$.

Se concluye el auto con la declaración del escribano Hurrutia de haberse personado en la casa, en su sala baja, donde comprobó que

“enfrente de la dicha puerta estauan en la pared dados golpes, que pareçió de pico de yerro o palanqueta, esto por alrededor donde estaua hecho

\footnotetext{
23 Idem.

24 Fols. $8 r^{2}-8 v^{0}$.

25 Fol. 8 v․․
} 
el dicho agujero, y en el suelo estaua vn pedazo de yeso blanco mal amasado que pareçia tapador del dicho agujero, y en el dicho agujero pareçia cabria cantidad de dinero" ${ }^{26}$.

Acompañaron al escribano como testigos de su visita Juan de Aguilera y Juan Bautista de Baeza y se notificó a una mujer que no quiso decir su nombre, seguramente la de Vallejo, que no se tapase el agujero ${ }^{27}$.

Esto es todo cuanto sabemos. Sobre la vertiente judicial de la cuestión, no es mucho. Ignoramos, pues, cuál pudo ser el veredicto e incluso qué organismo entendió definitivamente en ello, es decir, si en fin se acogió a la aludida concordia y vieron dos jueces del consejo de justicia y dos de la Inquisición como era preceptivo en tal supuesto. Empero, este aspecto de la cuestión, que posee interés propio sin duda, no es en modo alguno el más significativo en nuestro planteamiento. Nos ha interesado más analizar el caso en sí, a través de la declaración del inculpado y de dos testigos, sólo uno de ellos ajeno al mismo. Hemos podido así acercarnos a los comportamientos, no exentos de algún viso de picaresca de corto vuelo, de personas, como el propio encausado, cuya categoría moral, dentro de un estatus social no especialmente relevante pero tampoco deprimido, se supone debería estar más en consonancia con la dignidad de su posición o de su cargo.

Las declaraciones no parece que fueran textualmente creídas por el instructor ni por los jueces, que como primera provisión encarcelaron al tal Baltasar de Portales. Era difícil de creer que éste y su acompañante no extrajeran nada del agujero, cuya tapadera de yeso mal amasado denunciaba el recurso propio de quien ha de guardar un "tesoro" con precipitación, etc. Nótese, al respecto, que mientras que uno de los declarantes, Guevara (que al fin y al cabo reproduce lo que más o menos confidencialmente le dijera María de Morales, más que testigo, cómplice) dice que el agujero podria tener la dimensión de un chapín, el escribano Hurrutia sentencia que podria caber "cantidad de dinero".

Queda además la apenas disimulada - que no negada explícitamente- condición de morisco del acompañante; María de Morales afirma categórica que no portaba espada. Su misterioso embozamiento y su pertinaz mudez lo hacen más que sospechoso de ello; incluso que fuera el antiguo propietario de la casa temeroso de ser reconocido. La versión de

26 Fol. 9 rํ.

27 Idem. 
los tres jueces da por cierto que el silente acompañante es morisco traído de fuera. Es evidente que no era éste el único caso de semejante naturaleza que juzgaban: en ese supuesto creemos se enmarca la rotundidad del informe que elevan al rey, asi como la diligente encarcelación del actor; aunque habrá quien prefiera pensar que tanto celo tuviera más que ver con una mera cuestión jurisdiccional ante el declarado interés del Santo Oficio por hacerse con el caso. 